\title{
Late Imaging with [1-11 C]Acetate Improves Detection of Tumor Fatty Acid Synthesis with PET
}

\author{
David Y. Lewis ${ }^{1}$, Joan Boren ${ }^{1}$, Greg L. Shaw ${ }^{1}$, Robert Bielik ${ }^{1}$, Antonio Ramos-Montoya ${ }^{1}$, Timothy J. Larkin ${ }^{1,2}$, \\ Carla P. Martins ${ }^{3}$, David E. Neal ${ }^{1}$, Dmitry Soloviev ${ }^{1}$, and Kevin M. Brindle ${ }^{1,2}$ \\ ${ }^{I}$ Cancer Research United Kingdom-Cambridge Institute, University of Cambridge, Li Ka Shing Centre, Cambridge, United \\ Kingdom; ${ }^{2}$ Department of Biochemistry, University of Cambridge, Cambridge, United Kingdom; and ${ }^{3}$ MRC Cancer Unit, University \\ of Cambridge, Cambridge, United Kingdom
}

Tumors are often characterized by high levels of de novo fatty acid synthesis. The kinetics of acetate incorporation into tricarboxylic acid cycle intermediates and into lipids suggest that detection of tumors with $\left[1-{ }^{11} \mathrm{C}\right]$ acetate PET could be improved by imaging at later time points. Methods: The uptake and metabolism of $\left[1-{ }^{11} \mathrm{C}\right],\left[1-{ }^{13} \mathrm{C}\right]$, and $\left[1-{ }^{14} \mathrm{C}\right]$ acetate were measured in mouse prostate and lung cancer models to investigate the time course of ${ }^{11} \mathrm{C}$ label incorporation into tumor metabolites. Results: Radioactivity in the lipid fraction, as compared with the aqueous fraction, in extracts of $\mathrm{C} 4-2 \mathrm{~B}$ human prostate xenografts peaked at 90 min after $\left[1-{ }^{14} \mathrm{C}\right]$ acetate injection, which coincided with peak ${ }^{13} \mathrm{C}$ label incorporation into the fatty acids palmitate and stearate. Contrast between the tumor and tissues, such as blood and muscle, increased in PET images acquired over a period of 120 min after $\left[1-{ }^{11} \mathrm{C}\right]$ acetate injection, and Patlak plots were linear from $17.5 \mathrm{~min}$ after injection. Similar results were obtained in a genetically engineered K-ras ${ }^{\mathrm{G} 12 \mathrm{D}}$; p53null lung cancer model, in which the mean tumor-to-lung ratio at $90 \mathrm{~min}$ after $\left[1-{ }^{14} \mathrm{C}\right]$ acetate injection was 4.4 -fold higher than at $15 \mathrm{~min}$. Conclusion: These findings suggest that when imaging de novo fatty acid synthesis with $\left[1-{ }^{11} \mathrm{C}\right]$ acetate it is preferable to measure uptake at later time points, when the effects of perfusion and ${ }^{11} \mathrm{C}$ incorporation into tricarboxylic acid cycle intermediates and bicarbonate are declining. The data presented here suggest that future clinical PET scans of tumors should be acquired later than $30 \mathrm{~min}$, when tracer accumulation due to de novo fatty acid synthesis prevails.

Key Words: prostate; lung; cancer; $\left[{ }^{11} \mathrm{C}\right]$ acetate PET; mouse

J Nucl Med 2014; 55:1144-1149

DOI: 10.2967/jnumed.113.134437

\section{$\mathbf{P}$} ET measurements of $\left[1-{ }^{11} \mathrm{C}\right]$ acetate uptake have been used to assess tricarboxylic acid (TCA) cycle activity in normal and diseased heart tissue (1) and for visualizing fatty acid synthesis in tumors, where it has been used for imaging renal (2), prostate (3), liver (4), and lung cancer (5). Despite its limited availability, $\left[1-{ }^{11} \mathrm{C}\right]$ acetate has shown promise as a tracer for slow-growing tumors that do not show high levels of ${ }^{18}$ F-FDG uptake (6).

Received Oct. 30, 2013; revision accepted Mar. 19, 2014.

For correspondence or reprints contact: Kevin M. Brindle, Department of Biochemistry, Tennis Court Rd., Cambridge CB2 1GA and Cancer Research U.K.-Cambridge Institute, University of Cambridge, Li Ka Shing Centre, Cambridge, U.K.

E-mail: kmb1001@cam.ac.uk

Published online Apr. 28, 2014.

COPYRIGHT (C 2014 by the Society of Nuclear Medicine and Molecular Imaging, Inc.
Acetate is oxidized in the TCA cycle, mainly in the heart, kidney, and liver, and can also be used for de novo fatty acid synthesis (7-11), which requires several key enzymes, including acetyl-coenzyme A synthetase and fatty acid synthase. Fatty acid synthase is expressed predominantly in hepatocytes but is also present in white adipose, endometrial, and intestinal tissue $(8,11-13)$ and is overexpressed in several cancer types including prostate and lung $(7,14,15)$. The overexpression of the enzyme is associated with tumor aggressiveness and poor prognosis (16) and is a target for new cancer therapeutics and diagnostics $(7,10,15)$.

The TCA cycle results in rapid conversion of $\left[1-{ }^{11} \mathrm{C}\right]$ acetate into TCA cycle intermediates and into ${ }^{11} \mathrm{C}-\mathrm{CO}_{2}$, which is expired, whereas fatty acid synthesis results in the later accumulation of ${ }^{11} \mathrm{C}$ into lipids $(1,10)$. The choice of an optimal time for imaging, which balances loss of label in the pool of TCA cycle intermediates and incorporation into lipids with decay of the ${ }^{11} \mathrm{C}$ label (half-life, $20.4 \mathrm{~min}$ ), should enhance tumor contrast. However, there is little consensus in the literature about when to image or how much radioactivity to inject. In Supplemental Figure 1 (supplemental materials are available at http://jnm.snmjournals.org), we summarize some of the published $\left[1-{ }^{11} \mathrm{C}\right]$ acetate PET protocols used for imaging prostate, lung, liver, kidney, and brain tumors in the clinic. In these 28 studies, the average time frame for data analysis was $15 \mathrm{~min}$ after $\left[1-{ }^{11} \mathrm{C}\right]$ acetate injection (range, 2-47 $\mathrm{min}$ ), with most scans finishing before $30 \mathrm{~min}$. The average injected dose was $600 \mathrm{MBq}$ (range, 276-1,500 MBq) (Supplemental Table 1 provides references and further details).

The utility of $\left[1-{ }^{11} \mathrm{C}\right]$ acetate for tumor detection in the clinic is much debated (17), and the discrepancies in findings could probably be eliminated by the use of consistent imaging protocols. A recently published metaanalysis of $\left[1-{ }^{11} \mathrm{C}\right]$ acetate PET in prostate cancer concluded that further high-quality studies are needed (18). Studies reporting better acetate performance tend to use later imaging times (Supplemental Table 1). We show here, from an analysis of $\left[1-{ }^{11} \mathrm{C}\right],\left[1-{ }^{13} \mathrm{C}\right]$, and $\left[1-{ }^{14} \mathrm{C}\right]$ acetate uptake and metabolism in 2 mouse models of cancer, that later imaging time points are preferable for detection of signal originating from de novo fatty acid synthesis and therefore for improving tumor contrast.

\section{MATERIALS AND METHODS}

\section{Animals}

Male NSG mice were bred in-house and implanted subcutaneously in the lower flank with $2 \times 10^{6} \mathrm{C} 4-2 \mathrm{~B}$ human prostate cancer cells (Viromed Laboratories) in a volume of $50 \mu \mathrm{L}$ of phosphate-buffered saline and $50 \mu \mathrm{L}$ of Matrigel (Becton Dickinson Ltd.). Palpable tumors grew in approximately $5 \mathrm{wk}$, at which point the animals were injected with the various labeled acetate species. K-ras ${ }^{\mathrm{LSL}-\mathrm{G} 12 \mathrm{D} /+} ; \mathrm{p} 53^{\mathrm{fl} / \mathrm{fl}}$ mice 
were bred in-house under pathogen-free conditions. Lung tumors were induced by intranasal instillation of 8 -wk-old mice with adenovirusCRE $\left(5 \times 10^{7}\right.$ plaque-forming units/mouse), as described previously (18). Lung tumor imaging was performed $14-16 \mathrm{wk}$ after adenovirus treatment. All animal experiments were conducted in accordance with the U.K. Animals (Scientific Procedures) Act 1986 and were approved by local ethical review committees.

\section{Reagents}

$\left[1-{ }^{14} \mathrm{C}\right]$ acetate, sodium salt in ethanol (Perkin-Elmer) (specific activity, $2.1 \mathrm{GBq} / \mathrm{mmol}$ ), was prepared for injection by evaporating the ethanol and reconstituting in phosphate-buffered saline. Sodium $\left[1-{ }^{13} \mathrm{C}\right]$ acetate (Sigma-Aldrich) was dissolved in phosphate-buffered saline to produce a $2 \mathrm{~mol} / \mathrm{L}$ solution for injection. $\left[1-{ }^{11} \mathrm{C}\right]$ acetate was prepared as described previously (19) using an ACEMO (ITD) automated synthesizer. The ${ }^{11} \mathrm{CO}_{2}$ used in the synthesis was produced in a $16.5-\mathrm{MeV}$ PETTrace (GE Healthcare) cyclotron. Typically, radiochemical purity was greater than $99 \%$, volumetric activity was in the range of $0.3-0.4 \mathrm{MBq} / \mu \mathrm{l}$, and specific activity was $0.5-4.4 \mathrm{GBq} / \mu \mathrm{mol}$ at the time of injection.

\section{$\left[1-{ }^{11} \mathrm{C}\right],\left[1-{ }^{13} \mathrm{C}\right]$, and $\left[1-{ }^{14} \mathrm{C}\right] \mathrm{Acetate}$ Administration}

Mice were anesthetized using $1 \%-3 \%$ isoflurane in $100 \%$ oxygen and placed on a heated bed for tail vein cannulation. A cannula - consisting of a 30-gauge needle and 0.28 -mm $\varnothing$ polyethylene tubing — was placed in the lateral tail vein, and $200 \mu \mathrm{L}$ of labeled acetate - consisting of $300 \mu \mathrm{mol} /$ mouse of $\left[1-{ }^{13} \mathrm{C}\right]$ acetate, $100-300 \mathrm{kBq} /$ mouse $(47-143 \mathrm{nmol})$ of $\left[1-{ }^{14} \mathrm{C}\right]$ acetate, or $57.3-71.6 \mathrm{MBq} /$ mouse $(16-115 \mathrm{nmol})$ of $\left[1-{ }^{11} \mathrm{C}\right]$ acetate-were injected as a bolus, followed by $100 \mu \mathrm{L}$ of heparinized $(50 \mathrm{IU} / \mathrm{mL})$ saline flush. Mice were killed at 15,30,60,90, and $120 \mathrm{~min}$ after injection by cervical dislocation, as indicated. The tissues were collected and snap-frozen in liquid nitrogen, and metabolites were extracted using a 2-step methanol-chloroform-water protocol where appropriate (20).

\section{${ }^{14} \mathrm{C}$ Metabolite Analysis in C4-2B Xenografts}

For $\left[1-{ }^{14} \mathrm{C}\right]$ acetate metabolism studies, 8 or 9 mice were used at each time point $(30,60,90$, and 120 min after injection) and radioactivity in the aqueous and nonaqueous phases from the different tissues measured by liquid scintillation counting, as described previously (21). Results are expressed as percentage injected dose per gram of tissue or per milliliter of plasma.

\section{${ }^{14} \mathrm{C}$ Autoradiography in K-ras ${ }^{\mathrm{LSL}-G 12 D /+} ; \mathrm{p} 53^{\mathrm{fl} / \mathrm{fl}}$ Mice}

Frozen lungs from 3 mice at each time point (15 and 90 min after injection) were sectioned $(20 \mu \mathrm{m})$ at $-20^{\circ} \mathrm{C}(\mathrm{CM} 3050 \mathrm{~S}$ Cryostat; Leica), thaw-mounted onto microscope slides, and air-dried before being placed next to a storage phosphor screen for 4 wk (BAS-IV MS 2040; GE Healthcare). Slides were then stained using hematoxylin and eosin. Phosphor screens were imaged on a Typhoon Trio + (GE Healthcare) at a pixel size of $25 \mu \mathrm{m}$. Images were analyzed using ImageQuant TL software (GE Healthcare) and displayed as the mean ratio ( \pm SEM) of the corrected intensity values in tumor versus normal lung regions. Ratios were compared using an unpaired, 2-tailed $t$ test (Prism, version 6.01; GraphPad).

\section{${ }^{13} \mathrm{C}$ Metabolite Analysis by Gas Chromatography-Mass Spectrometry (GC-MS) in C4-2B Xenografts}

Aqueous extracts were derivatized with Tri-Sil HTP reagent (Thermo Fisher Scientific) at $42^{\circ} \mathrm{C}$ for $30 \mathrm{~min}$. Nonaqueous extracts were derivatized using methanolic $\mathrm{HCl}(0.5 \mathrm{~mol} / \mathrm{L}$; Sigma Aldrich) at $70^{\circ} \mathrm{C}$ overnight, dried under nitrogen, and dissolved in hexane. Samples were injected into a GC-time-of-flight-MS (Pegasus GC-TOF-MS system; Leco) and run using methods described previously $(22,23)$. Chromatograms were analyzed using ChromaTOF software (Leco). Peak intensities were normalized to the base peak and corrected for natural ${ }^{13} \mathrm{C}$ abundance. Molar enrichment was calculated using the mass isotopomer distribution analysis approach (24). Time points were compared using a 1-way ANOVA, and $P$ values were reported (version 6.01, Prism; GraphPad). The supplemental information provides further GC-MS methods.

\section{PET Image Acquisition and Analysis}

Three prostate- and 5 lung tumor-bearing mice were administered $\left[1-{ }^{11} \mathrm{C}\right]$ acetate while in the bore of a NanoPET/CT scanner (Mediso). The spatial resolution and sensitivity of the scanner in the center of the field of view were $1 \mathrm{~mm}$ and $7.7 \%$, respectively (25). Data were acquired in list-mode format. A corresponding CT image was acquired for anatomic registration. PET images were reconstructed using a 2dimensional ordered-subset expectation maximization method using 5 iterations and 6 subsets into 28 time bins $(4 \times 15,4 \times 60,17 \times 300$, and $3 \times 600 \mathrm{~s}$ ). All images were normalized and corrected for decay, dead time, and random events, producing images with $283-\mu \mathrm{m}$ isotropic voxels. No attenuation correction was applied.

Dynamic PET images were analyzed using Vivoquant 1.23 software (InviCRO) with which a 3-dimensional region of interest was drawn over the target tissues. The mean radioactivity was converted into standardized uptake value (SUV), and graphical linearization of the kinetic data was created using the method of Patlak (26), with the left ventricle used as a reference and for calculation of tumor-to-blood ratios. Ratios were compared using a paired, 2-tailed $t$ test (Prism, version 6.01; GraphPad).

\section{RESULTS}

In animals bearing prostate tumor xenografts injected with $\left[1-{ }^{14} \mathrm{C}\right]$ acetate, the total ${ }^{14} \mathrm{C}$ concentration in tissues was maximal

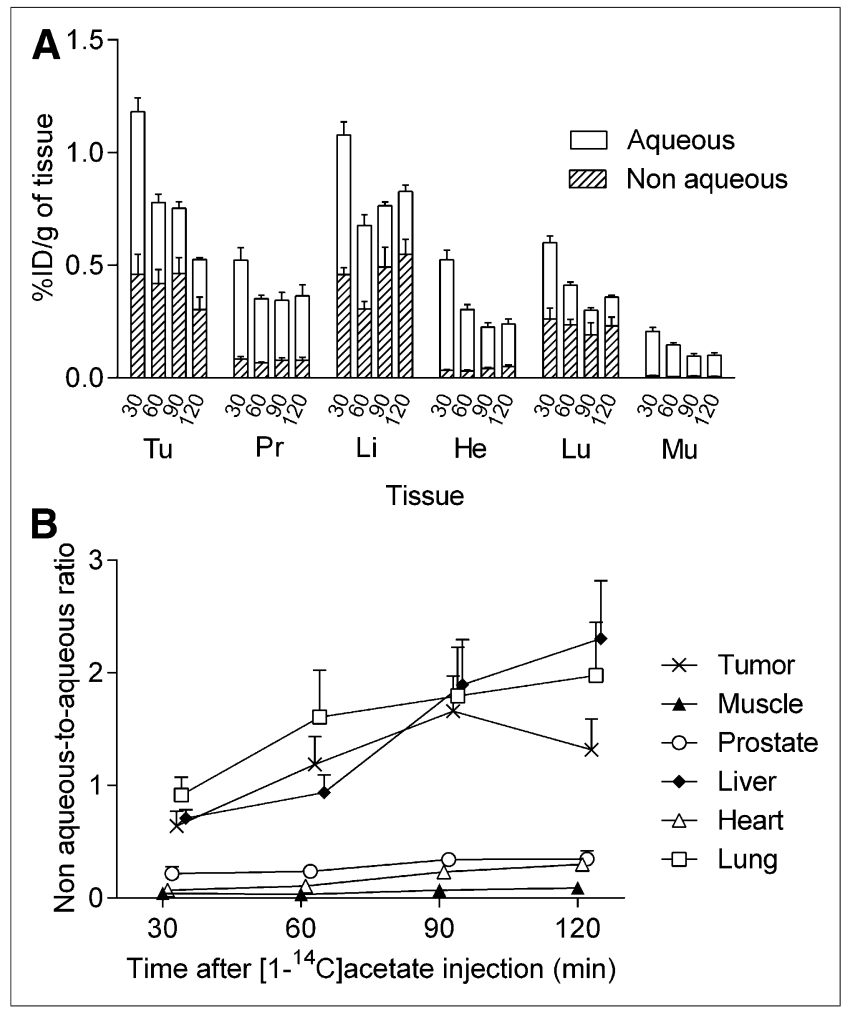

FIGURE 1. $\left[1-{ }^{14} \mathrm{C}\right]$ acetate incorporation into aqueous and nonaqueous phases of tissue extracts after intravenous injection in prostate tumor-bearing mice. (A) Mice were killed and tissues removed at indicated times (min). Error bars represent mean \pm SEM ( $n=8-9$ mice). (B) Ratio between ${ }^{14} \mathrm{C}$ content in aqueous and nonaqueous phases of tissue extracts prepared at indicated times $(\mathrm{min})$ after intravenous injection of $\left[1-{ }^{14} \mathrm{C}\right]$ acetate. Points represent mean \pm SEM $(n=8-9$ mice). \%ID/g = percentage injected dose per gram; $\mathrm{He}=$ heart; $\mathrm{Li}=$ liver; $\mathrm{Lu}=$ lung; $\mathrm{Mu}=$ muscle; $\mathrm{Pr}=$ prostate; $\mathrm{Tu}=$ tumor. 


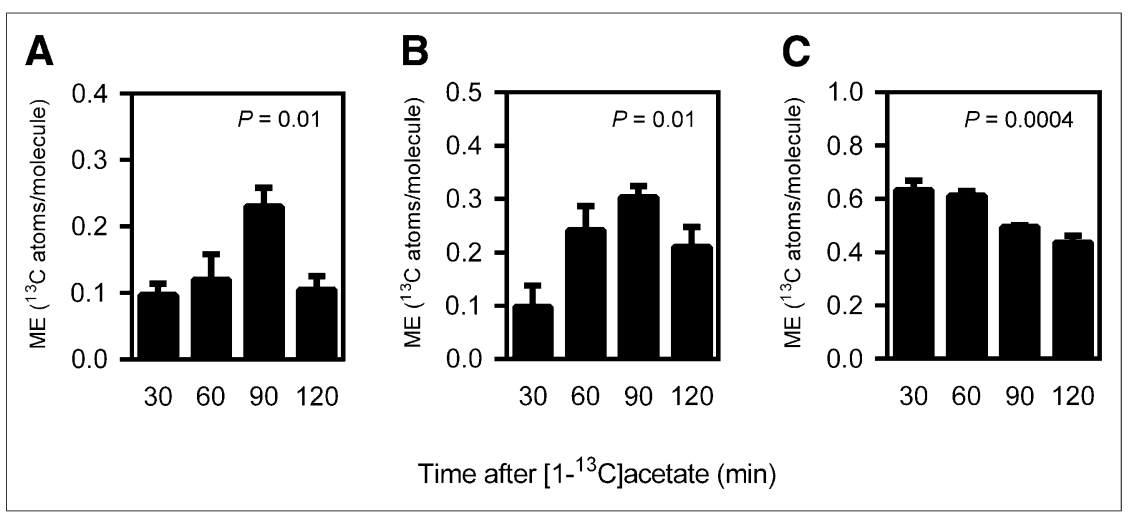

FIGURE 2. GC-MS measurements of $\left[1-{ }^{13} \mathrm{C}\right]$ acetate incorporation into tumor metabolites in nonaqueous and aqueous phases of tumor extracts of prostate tumor-bearing mice: palmitate $(A)$, stearate $(B)$, and glutamate $(C)$. Incorporation is expressed as molar enrichment (ME), which is average number of ${ }^{13} \mathrm{C}$ atoms substituted per molecule (bars represent mean $\pm \mathrm{SEM}, n=3-4$ mice). $P$ values are from 1-way ANOVA comparisons of time points for each metabolite and are shown in top-right-hand corner of respective bar charts.

at the first measurement time point, $30 \mathrm{~min}$ after $\left[1-{ }^{14} \mathrm{C}\right]$ acetate injection, and decreased progressively thereafter (Fig. 1A). Label in the aqueous phase decreased between 30 and 120 min after injection whereas label in the nonaqueous phase was relatively constant, leading to a progressive increase in the labeling of lipids

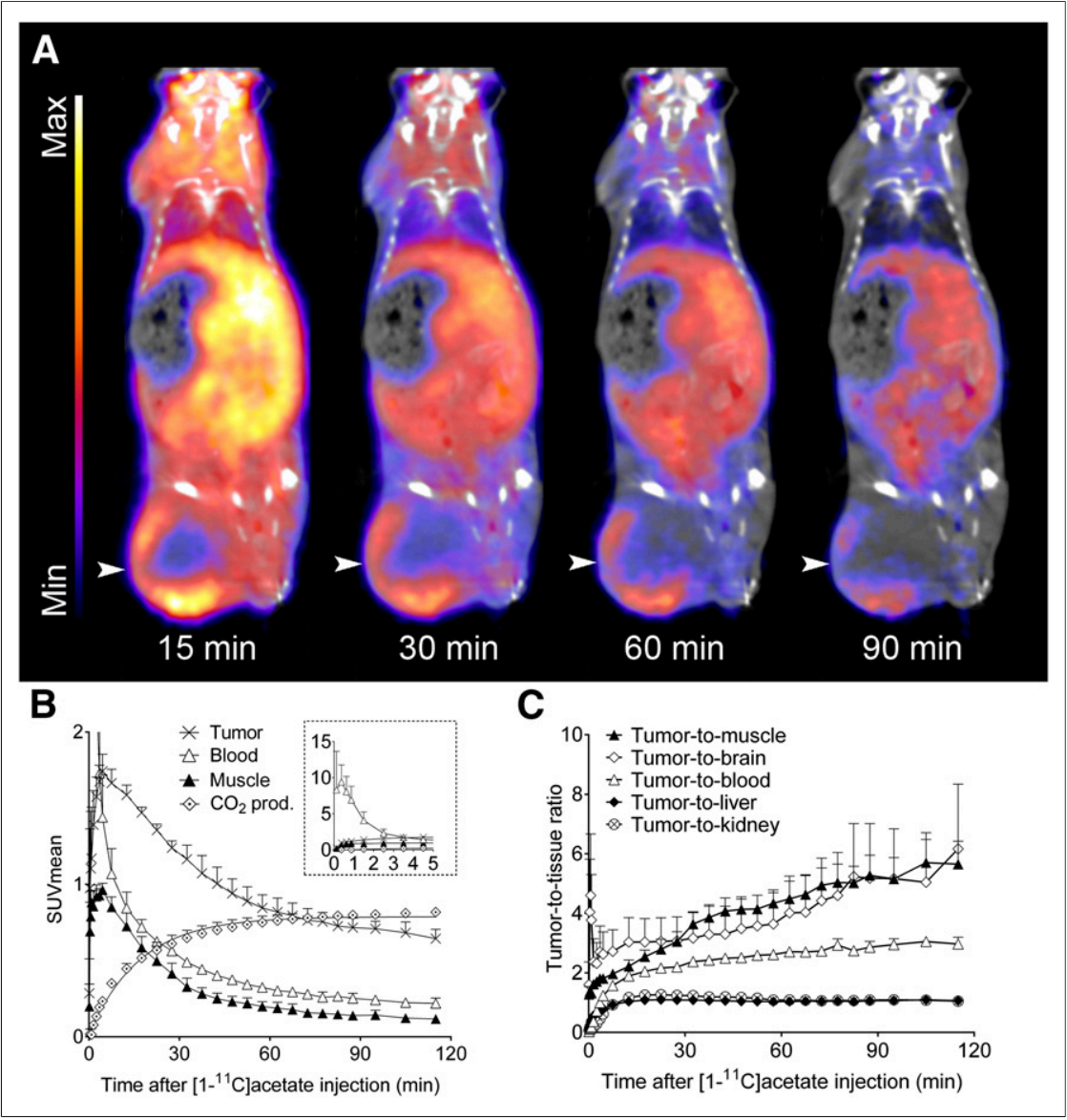

FIGURE 3. (A) Coronal [1-11 C]acetate PET/CT images acquired from prostate tumor-bearing mice at indicated times after radiotracer injection. Tumor is indicated by arrowhead. (B) Tissue time-activity curves (insert shows first $5 \mathrm{~min}$ ). (C) Tumor-to-tissue activity ratios. ROls were drawn over tumor and other tissues (mean \pm SEM; $n=3$ mice). Max = maximum; Min = minimum; prod. = production. relative to the water-soluble metabolites. This increase was most marked in the tumor, liver, and lung (Fig. 1B). The time course of labeling in the lipid and water-soluble metabolite pools was investigated further by injecting animals with $\left[1-{ }^{13} \mathrm{C}\right]$ acetate and analyzing the lipids and water-soluble metabolites in tumor extracts using GC-MS and ${ }^{13} \mathrm{C}$ nuclear magnetic resonance spectroscopy. The incorporation of ${ }^{13} \mathrm{C}$ label in palmitate and stearate reached a peak at $90 \mathrm{~min}$ after acetate injection, ${ }^{13} \mathrm{C}$ label in glutamate decreased over $2 \mathrm{~h}$ (Figs. 2A-2C), and the level of injected acetate declined between 30 and 90 min (Supplemental Fig. 2). The levels of ${ }^{13} \mathrm{C}$ enrichment in citrate, oleate, and cholesterol did not vary significantly over time.

Increasing tumor contrast in the prostate tumor-bearing mice was readily observable in the PET/CT images obtained at later time points (Fig. 3A). The highest mean SUV in the tumor occurred 4.5 min after injection of $\left[1-{ }^{11} \mathrm{C}\right]$ acetate $(1.74 \pm 0.06 ; n=3$; Fig. $3 \mathrm{~B})$, but the highest contrast between the tumor and other tissues occurred at later time points (Fig. 3C). The highest tumor-to-blood, tumor-to-brain, and tumor-to-muscle activity ratios were $3.1 \pm 0.2$, $6.2 \pm 2.2$, and $5.7 \pm 0.8$, occurring at 105 , 115 , and $105 \mathrm{~min}$, respectively, after injection (Fig. 3C). The maximum tumor-to-liver $(1.1 \pm 0.1)$ and tumor-to-kidney $(1.3 \pm 0.1)$ ratios plateaued earlier at $22.5 \mathrm{~min}$ after injection (Fig. 3C). The maximum mean SUV in the blood pool, as measured in the left ventricle, was $9.4 \pm 1.4(n=3)$ at $23 \mathrm{~s}$. Excretion of ${ }^{11} \mathrm{CO}_{2}$ (Fig. 3B) was determined by measuring the loss of radioactivity from the whole animal and correcting for ${ }^{11} \mathrm{C}$ half-life (20.4 min). This showed a monoexponential decay with a half-life of $11.7 \mathrm{~min}$ $(n=3)$. Patlak plots were linear $\left(R^{2}=0.93\right.$; $P<0.0001)$ from $17.5 \mathrm{~min}$ after injection until the end of the scan at $120 \mathrm{~min}$ (Fig. 4).

We further examined $\left[1-{ }^{11} \mathrm{C}\right]$ acetate uptake in a K-ras ${ }^{\mathrm{G} 12 \mathrm{D}}$; p53 $^{\text {null }}$ model of lung cancer. Increasing lung tumor contrast relative to other organs was observed from 15 min onward despite a decreasing tumor mean SUV. Peak contrast occurred between 90 and $120 \mathrm{~min}$ after $\left[1-{ }^{11} \mathrm{C}\right]$ acetate injection (Supplemental Figs. 3A and 3B). Mice imaged at $90 \mathrm{~min}$ showed high tumor contrast, whereas non-tumor-bearing wildtype mice had little measurable activity in the lung (Figs. 5A and 5B). $\left[1-{ }^{11} \mathrm{C}\right]$ acetate tumor-to-muscle ratios increased 2-fold between $30(1.9 \pm 0.5)$ and $90 \min (4.0 \pm 0.4$; $P=0.01 ; n=3$ mice; Fig. 5C). Lung tumors were verified by histology and $\left[1-{ }^{14} \mathrm{C}\right]$ acetate autoradiography. The ratio of the counts in the tumor to surrounding normal lung tissue increased 4.4-fold from $12.7 \pm 0.9$ at $15 \mathrm{~min}$ to $55.4 \pm 2.8$ at 


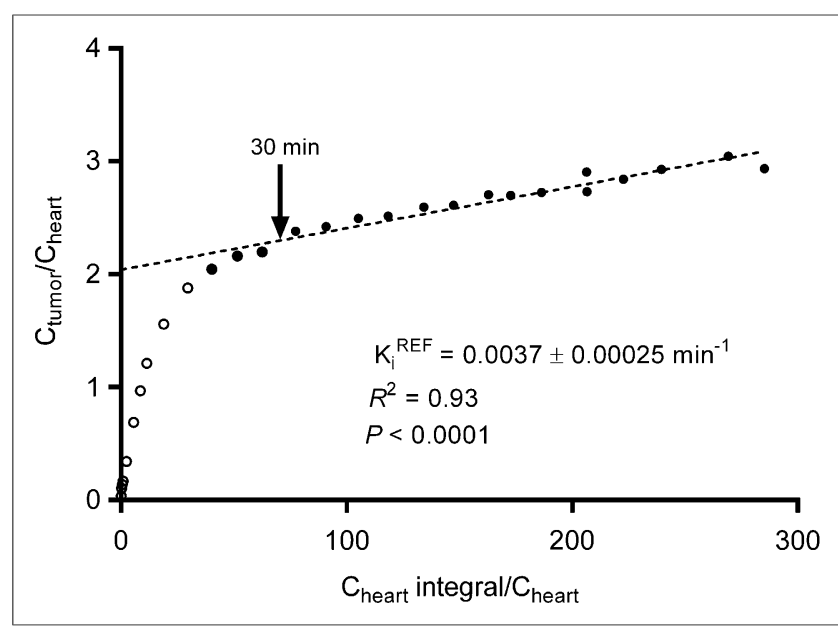

FIGURE 4. Patlak plot showing $\mathrm{K}_{\mathrm{i}}$ (influx rate constant) values in prostate tumor-bearing mice. Points used for linear regression are shown with $\bullet$ and reflect data from $17.5 \mathrm{~min}$ after $\left[1-{ }^{-11} \mathrm{C}\right]$ acetate injection. Arrow indicates $30 \mathrm{~min}$ after injection. $\mathrm{K}_{\mathrm{i}}^{\mathrm{REF}}=$ reference influx constant.
90 min after injection $(P=0.0001 ; n=3$ mice at each time point $)$ (Figs. 6A and 6B).

\section{DISCUSSION}

We have investigated here the effects of image timing on tumor contrast in PET images obtained after $\left[1-{ }^{11} \mathrm{C}\right]$ acetate injection into mice bearing subcutaneous prostate tumors or genetically engineered Kras-driven lung tumors. The ratio of activity between tumor and other tissues increased progressively up to $90 \mathrm{~min}$ after acetate injection. Measurements of $\left[1-{ }^{14} \mathrm{C}\right]$ and $\left[1-{ }^{13} \mathrm{C}\right]$ acetate in extracts of the prostate tumors showed that at the early time points most of the label was in the aqueous fraction, which includes TCA cycle metabolites and bicarbonate. Clinical data show that $70 \%-$ $80 \%$ of injected acetate is metabolized to bicarbonate by 10 $15 \mathrm{~min}(27,28)$, and although we did not measure bicarbonate production, a substantial fraction $(60.3 \%)$ of the injected dose was expired as ${ }^{11} \mathrm{CO}_{2}$ in the first $15 \mathrm{~min}$. At later times, most of the label was in the nonaqueous fraction, which includes fatty acids such as palmitate and stearate. Label incorporation into lipids was rapid, as evidenced by the ${ }^{14} \mathrm{C}$ experiments, with tumor uptake already maximal at the first time point, which was $30 \mathrm{~min}$ after acetate injection. Our xenograft results agree with $\left[1-{ }^{14} \mathrm{C}\right]$ acetate studies
A

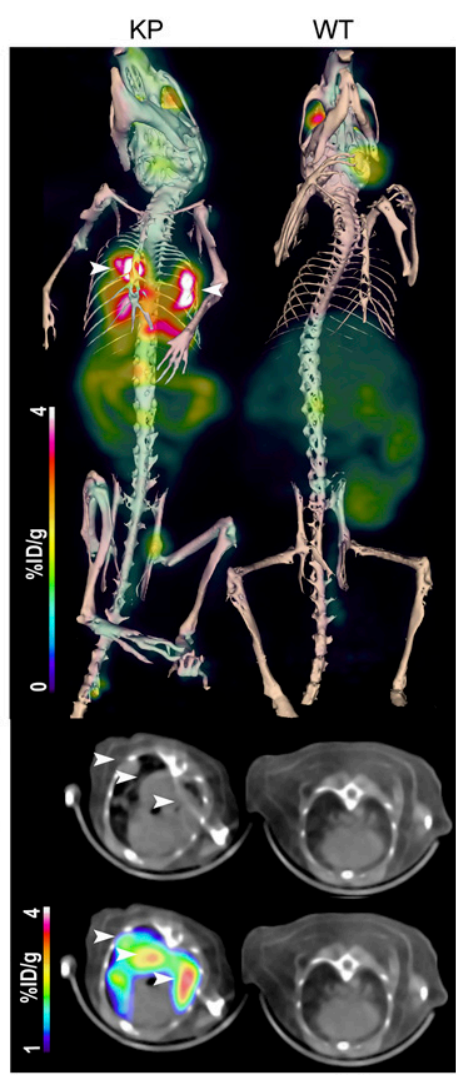

B

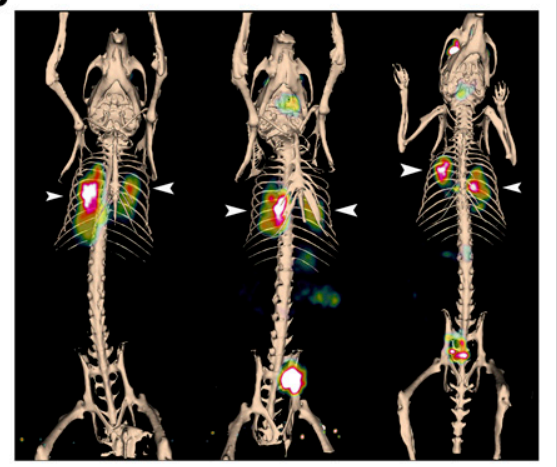

C

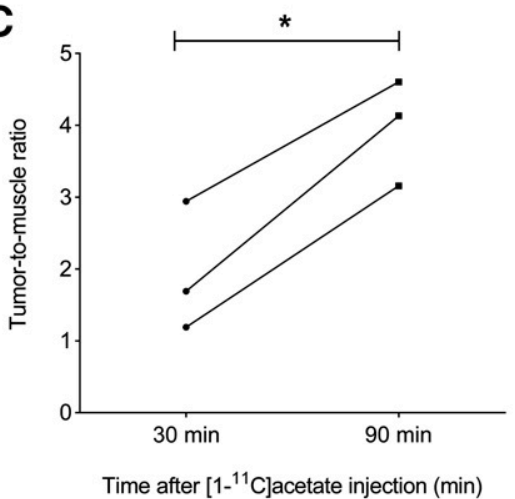

FIGURE 5. [1-11 C]acetate uptake in K-ras ${ }^{\mathrm{G} 12 \mathrm{D}}$; p53null (KP) lung tumor-bearing mice. (A) PET/CT images acquired over period of $20 \mathrm{~min}$ starting at $80 \mathrm{~min}$ after injection of $150 \mathrm{MBq}$ of [1-11 C]acetate: PET/CT maximum-intensity projections from anterior view (top), CT transverse slices at level of lungs (middle), and corresponding transverse $\left[1-{ }^{11} \mathrm{C}\right]$ acetate PET/CT images (bottom). Lung tumors are indicated with arrowheads. Images of tumor-bearing mouse (KP) are shown on left, and corresponding images obtained from a wild-type (WT) mouse, with no tumors, are shown on right. (B) Three KP lung tumor-bearing mice imaged at $90 \mathrm{~min}$ after injection, thresholded to visualize high tumor uptake (indicated by arrowheads). (C) Tumor-to-muscle activity ratios in lung tumor-bearing KP mice imaged at 30 and 90 min after injection $\left(n=3\right.$ mice; $\left.{ }^{*} P=0.01\right) . \% \mathrm{ID} / \mathrm{g}=$ percentage injected dose per gram. on cultured tumor cells, in which ${ }^{14} \mathrm{C}$ incorporation into lipid peaked at $25 \mathrm{~min}$ (29).

Maximum ${ }^{13} \mathrm{C}$ label incorporation into palmitate and stearate in the prostate tumors occurred at approximately $90 \mathrm{~min}$ after acetate injection. Although the $\left[1-{ }^{13} \mathrm{C}\right]$ acetate concentration was 1,000 times higher than the concentrations of the radionuclide labeled acetates, this timing was similar to that observed with ${ }^{11} \mathrm{C}$ - and ${ }^{14} \mathrm{C}$-acetate.

The liver and lung, which also have relatively high rates of de novo fatty acid synthesis (15), showed the same pattern of ${ }^{14} \mathrm{C}$ label incorporation into the lipid pool as the tumors (Fig. 1B). The ratios of activity in the tumor, compared with that in tissues other than lung and liver, peaked at $90 \mathrm{~min}$ after injection, suggesting that imaging at later time points would be better for improving tumor contrast in PET images (Supplemental Fig. 4).

Patlak analysis suggested that for the first 17.5 min after $\left[1{ }^{11} \mathrm{C}\right]$ acetate injection, the reversibly labeled tumor pool, representing TCA cycle metabolites and bicarbonate, was dominant, whereas the irreversibly labeled pool, representing tumor lipid, dominated after $17.5 \mathrm{~min}$. Previous clinical studies showing nonlinear Patlak plots may have finished scanning too early for the irreversible compartment to dominate (30). Our data support this assertion because at 30 min there was insufficient data to show linearity on Patlak plots (Fig. 4).

Similar observations were made in a K-ras ${ }^{\mathrm{G} 12 \mathrm{D}}$; p53 $^{\text {null }}$ model of non-small cell 


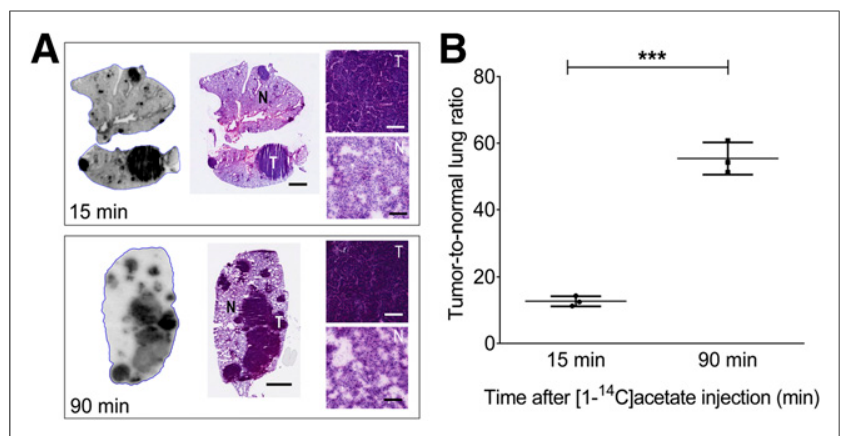

FIGURE 6. $\left[1{ }^{14} \mathrm{C}\right]$ acetate uptake in $\mathrm{K}-\mathrm{ras}^{\mathrm{G} 12 \mathrm{D}}$; p53null $(\mathrm{KP})$ lung tumorbearing mice. (A) Autoradiography at 15 (top left) and $90 \mathrm{~min}$ (bottom left) after acetate injection. Same sections stained with hematoxylin and eosin (top middle and bottom middle, respectively; horizontal bars represent $2 \mathrm{~mm}$ ). On right, high magnification of tumors (T) and normal lungs (N) from regions indicated is shown. Horizontal bars represent $100 \mu \mathrm{m}$. (B) Background-corrected activity ratios between tumor and normal lung at 15 and 90 min after $\left[1-{ }^{14} \mathrm{C}\right]$ acetate injection $\left({ }^{\star \star *} P=0.0001 ; n=3\right.$ mice at each time point). Activities in 18-24 lung tumors from each mouse were averaged.

lung adenocarcinoma, in which we observed differences in $\left[1-{ }^{11} \mathrm{C}\right]$ acetate contrast in tumors between early and late imaging time points (Fig. 5; Supplemental Fig. 3). PET images acquired at 90 min after injection produced higher tumor contrast, which was confirmed by ${ }^{14} \mathrm{C}$ autoradiography. The increase in contrast between the tumor and surrounding normal tissue was due to a decrease in normal lung uptake, rather than an increase in tumor uptake at later time points.

Many clinical $\left[1-{ }^{11} \mathrm{C}\right]$ acetate PET studies in cancer have reached differing conclusions, with some showing encouraging results $(2,27,31)$ and others showing poor performance of the tracer (Supplemental Table 1) (30,32). A possible explanation for this discrepancy is that the positive reports have used later time frames for image analysis. For example, in renal carcinoma, when images were acquired between 20 and $50 \mathrm{~min}$ after injection, $70 \%$ of diagnosed tumors were positive on the PET scan (31), whereas in another study, when images were acquired between 5 and $30 \mathrm{~min}$ after injection, high tracer uptake was only detected in $16 \%$ (32). Our work appears to contradict previous comparisons between early and late time points with $\left[1-{ }^{11} \mathrm{C}\right]$ acetate, which have shown few differences $(27,33)$; however, early and late in these studies were 6-10 and 15-20 min, respectively. This is broadly in agreement with our 5-10 $\min (1.67 \pm 0.05)$ and $15-20 \min (1.47 \pm 0.02)$ tumor SUVs in the prostate tumors, so it seems possible that late imaging in these studies was not late enough to see improvements in tumor contrast. Indeed the early-to-late SUV ratios for prostate cancer in both of these papers were about 1 , suggesting that label in the aqueous pool of TCA metabolites and bicarbonate had not started to decline $(27,33)$. Recent discussion has pointed to the importance of dynamic acquisition for correct interpretation of $\left[1-{ }^{11} \mathrm{C}\right]$ acetate PET studies $(30,34,35)$. Although neither of these groups saw a difference between prostate cancer and benign prostatic hyperplasia, they stopped imaging $30 \mathrm{~min}$ or earlier after acetate injection. To our knowledge, no study comparing primary prostate cancer and benign prostatic hyperplasia has imaged beyond $30 \mathrm{~min}$; the data presented here suggest that this now is warranted. Recent metaanalysis of $24\left[1-{ }^{11} \mathrm{C}\right]$ acetate PET studies in prostate cancer also suggest that imaging beyond 45 min could be beneficial (18).

In summary, to image, using $\left[1-{ }^{11} \mathrm{C}\right]$ acetate PET, the high levels of de novo fatty acid synthesis that are a characteristic of tumors, it is preferable to delay imaging until later time points, despite significant loss of signal due to the short half-life $(20.4 \mathrm{~min})$ of the ${ }^{11} \mathrm{C}$ label. Late imaging counting rates could be improved by injecting more radioactivity; the effective dose rate for acetate is $0.005 \mathrm{mSv} / \mathrm{MBq}(36)$ as compared with $0.019 \mathrm{mSv} / \mathrm{MBq}$ for ${ }^{18} \mathrm{~F}-\mathrm{FDG}$ (37). The injected activity could be increased to 1,427 $\mathrm{MBq}$ (2.4 times the average $\left[1-{ }^{11} \mathrm{C}\right]$ acetate injected dose used currently) without exceeding the radiation exposure of a 370$\mathrm{MBq}{ }^{18}$ F-FDG PET scan. Therefore, at $60 \mathrm{~min}$ after injection, and neglecting clearance, there would be $185 \mathrm{MBq}$ of $\left[1-{ }^{11} \mathrm{C}\right]$ acetate, as compared with $258 \mathrm{MBq}$ of ${ }^{18} \mathrm{~F}-\mathrm{FDG}$.

There are some potential limitations to our study. The peak tumor $\left[1-{ }^{11} \mathrm{C}\right]$ acetate uptake observed here was at a time (4.5 min) similar to that observed in previous clinical studies (27); however, the kinetics of clearance appear to be faster in the mouse. The half-life for loss of ${ }^{11} \mathrm{C}$ as $\mathrm{CO}_{2}$ was estimated here at $11.7 \mathrm{~min}$, which is less than the 45-60 min reported for larger animals and humans (28). Therefore, the optimal time for $\left[1-{ }^{11} \mathrm{C}\right]$ acetate imaging of tumor fatty acid synthesis in the clinic may be even later than the times suggested by this study, when the decay of the ${ }^{11} \mathrm{C}$ label may start to become a problem. Finally, we chose not to use a metabolite-corrected input function for kinetic analysis because the application of an acetate metabolism model (27) to our data did not change appreciably the time over which linearity was observed in the Patlak plot.

\section{CONCLUSION}

When imaging tumors with $\left[1-{ }^{11} \mathrm{C}\right]$ acetate, it is preferable to measure uptake at later time points, when the effects of perfusion and ${ }^{11} \mathrm{C}$ incorporation into TCA cycle intermediates and bicarbonate are in decline and there is increased incorporation into fatty acids. The data presented here suggest that future clinical studies should examine PET scans acquired later than $30 \mathrm{~min}$, when tracer accumulation due to de novo fatty acid synthesis prevails.

\section{DISCLOSURE}

The costs of publication of this article were defrayed in part by the payment of page charges. Therefore, and solely to indicate this fact, this article is hereby marked "advertisement" in accordance with 18 USC section 1734 . This study was supported by a Cancer Research U.K. program grant (no. 17242). CPM was supported by the Medical Research Council. No other potential conflict of interest relevant to this article was reported.

\section{ACKNOWLEDGMENTS}

We thank Matt Clayton for his help with animal experiments and the radiochemistry team in the Wolfson Brain Imaging Centre for tracer production.

\section{REFERENCES}

1. Porenta G, Cherry S, Czernin J, et al. Noninvasive determination of myocardial blood flow, oxygen consumption and efficiency in normal humans by carbon-11 acetate positron emission tomography imaging. Eur J Nucl Med. 1999;26:1465-1474.

2. Shreve P, Chiao PC, Humes HD, Schwaiger M, Gross MD. Carbon-11-acetate PET imaging in renal disease. J Nucl Med. 1995;36:1595-1601.

3. Kotzerke J, Volkmer BG, Neumaier B, Gschwend JE, Hautmann RE, Reske SN. Carbon-11 acetate positron emission tomography can detect local recurrence of prostate cancer. Eur J Nucl Med Mol Imaging. 2002;29:1380-1384.

4. Ho CL, Yu SC, Yeung DW. ${ }^{11} \mathrm{C}$-acetate PET imaging in hepatocellular carcinoma and other liver masses. J Nucl Med. 2003;44:213-221. 
5. Shibata $\mathrm{H}$, Nomori $\mathrm{H}$, Uno $\mathrm{K}$, et al. ${ }^{11} \mathrm{C}$-acetate for positron emission tomography imaging of clinical stage IA lung adenocarcinoma: comparison with ${ }^{18} \mathrm{~F}$ fluorodeoxyglucose for imaging and evaluation of tumor aggressiveness. Ann Nucl Med. 2009;23:609-616.

6. Grassi I, Nanni C, Allegri V, et al. The clinical use of PET with ${ }^{11} \mathrm{C}$-acetate. Am J Nucl Med Mol Imaging. 2012;2:33-47.

7. Kuhajda FP. Fatty acid synthase and cancer: new application of an old pathway. Cancer Res. 2006;66:5977-5980.

8. Yoshimoto M, Waki A, Yonekura Y, et al. Characterization of acetate metabolism in tumor cells in relation to cell proliferation: acetate metabolism in tumor cells. Nucl Med Biol. 2001;28:117-122.

9. Soloviev D, Fini A, Chierichetti F, Al-Nahhas A, Rubello D. PET imaging with ${ }^{11} \mathrm{C}$-acetate in prostate cancer: a biochemical, radiochemical and clinical perspective. Eur J Nucl Med Mol Imaging. 2008;35:942-949.

10. Vāvere AL, Kridel SJ, Wheeler FB, Lewis JS. $1{ }^{11} \mathrm{C}$-acetate as a PET radiopharmaceutical for imaging fatty acid synthase expression in prostate cancer. $\mathrm{J} \mathrm{Nucl}$ Med. 2008;49:327-334.

11. Yun M, Bang SH, Kim JW, Park JY, Kim KS, Lee JD. The importance of acetyl coenzyme A synthetase for ${ }^{11} \mathrm{C}$-acetate uptake and cell survival in hepatocellular carcinoma. J Nucl Med. 2009;50:1222-1228.

12. Luong A, Hannah VC, Brown MS, Goldstein JL. Molecular characterization of human acetyl-CoA synthetase, an enzyme regulated by sterol regulatory element-binding proteins. J Biol Chem. 2000;275:26458-26466.

13. Yoshii Y, Waki A, Furukawa T, et al. Tumor uptake of radiolabeled acetate reflects the expression of cytosolic acetyl-CoA synthetase: implications for the mechanism of acetate PET. Nucl Med Biol. 2009;36:771-777.

14. Orita H, Coulter J, Tully E, Kuhajda FP, Gabrielson E. Inhibiting fatty acid synthase for chemoprevention of chemically induced lung tumors. Clin Cancer Res. 2008;14:2458-2464.

15. Menendez JA, Lupu R. Fatty acid synthase and the lipogenic phenotype in cancer pathogenesis. Nat Rev Cancer. 2007;7:763-777.

16. Rossi S, Graner E, Febbo P, et al. Fatty acid synthase expression defines distinct molecular signatures in prostate cancer. Mol Cancer Res. 2003;1: 707-715.

17. Nanni C, Castellucci P, Farsad M, Rubello D, Fanti S. ${ }^{11} \mathrm{C} /{ }^{18} \mathrm{~F}$-choline PET or ${ }^{11} \mathrm{C} /{ }^{18} \mathrm{~F}$-acetate PET in prostate cancer: may a choice be recommended? Eur $\mathrm{J}$ Nucl Med Mol Imaging. 2007;34:1704-1705.

18. Mohsen B, Giorgio T, Rasoul ZS, et al. Application of ${ }^{11} \mathrm{C}$-acetate positronemission tomography (PET) imaging in prostate cancer: systematic review and meta-analysis of the literature. BJU Int. 2013;112:1062-1072.

19. Soloviev D, Tamburella C. Captive solvent $\left[{ }^{11} \mathrm{C}\right]$ acetate synthesis in GMP conditions. Appl Radiat Isot. 2006;64:995-1000.
20. Wu H, Southam AD, Hines A, Viant MR. High-throughput tissue extraction protocol for NMR- and MS-based metabolomics. Anal Biochem. 2008;372:204-212.

21. Boren J, Brindle KM. Apoptosis-induced mitochondrial dysfunction causes cytoplasmic lipid droplet formation. Cell Death Differ. 2012;19:1561-1570.

22. Metallo CM, Walther JL, Stephanopoulos G. Evaluation of ${ }^{13} \mathrm{C}$ isotopic tracers for metabolic flux analysis in mammalian cells. J Biotechnol. 2009;144:167-174.

23. Perroud B, Lee J, Valkova N, et al. Pathway analysis of kidney cancer using proteomics and metabolic profiling. Mol Cancer. 2006;5:64-80.

24. Lee WN. Stable isotopes and mass isotopomer study of fatty acid and cholesterol synthesis: a review of the MIDA approach. Adv Exp Med Biol. 1996;399:95-114.

25. Szanda I, Mackewn J, Patay G, et al. National Electrical Manufacturers Association NU-4 performance evaluation of the PET component of the NanoPET/CT preclinical PET/CT scanner. J Nucl Med. 2011;52:1741-1747.

26. Patlak CS, Blasberg R, Fenstermacher J. Graphical evaluation of blood-to-brain transfer constants from multiple-time uptake data. J Cereb Blood Flow Metab. 1983;3:1-7.

27. Schiepers C, Hoh CK, Nuyts J, et al. $1{ }^{11} \mathrm{C}$-acetate kinetics of prostate cancer. $J$ Nucl Med. 2008;49:206-215.

28. Shields AF, Graham MM, Kozawa SM, et al. Contribution of labeled carbon dioxide to PET imaging of carbon-11-labeled compounds. J Nucl Med. 1992;33:581-584.

29. Salem N, Kuang Y, Corn D, et al. [(Methyl)1-11 C]-acetate metabolism in hepatocellular carcinoma. Mol Imaging Biol. 2011;13:140-151.

30. Mena E, Turkbey B, Mani H, et al. ${ }^{11} \mathrm{C}$-acetate PET/CT in localized prostate cancer: a study with MRI and histopathologic correlation. J Nucl Med. 2012;53:538-545.

31. Oyama N, Okazawa H, Kusukawa N, et al. ${ }^{11} \mathrm{C}$-acetate PET imaging for renal cell carcinoma. Eur J Nucl Med Mol Imaging. 2009;36:422-427.

32. Kotzerke J, Linne C, Meinhardt M, et al. $\left[1-{ }^{11} \mathrm{C}\right]$ acetate uptake is not increased in renal cell carcinoma. Eur J Nucl Med Mol Imaging. 2007;34:884-888.

33. Kato T, Tsukamoto E, Kuge $\mathrm{Y}$, et al. Accumulation of $\left[{ }^{11} \mathrm{C}\right]$ acetate in normal prostate and benign prostatic hyperplasia: comparison with prostate cancer. Eur J Nucl Med Mol Imaging. 2002;29:1492-1495.

34. Adler S, Kurdziel K, Lindenberg L, Choyke P, Mena E. Reply: dynamic PET/CT with ${ }^{11} \mathrm{C}$-acetate in prostate cancer. J Nucl Med. 2013;54:326-327.

35. Schiepers C, Huang S-C, Dahlbom M. Dynamic PET/CT with ${ }^{11} \mathrm{C}$-acetate in prostate cancer. J Nucl Med. 2013;54:326.

36. Seltzer MA, Jahan SA, Sparks R, et al. Radiation dose estimates in humans for ${ }^{11}$ C-acetate whole-body PET. J Nucl Med. 2004;45:1233-1236.

37. Brix G, Lechel U, Glatting G, et al. Radiation exposure of patients undergoing whole-body dual-modality ${ }^{18}$ F-FDG PET/CT examinations. J Nucl Med. 2005;46: 608-613. 